\title{
ASSESSMENT OF THE NON-LINEAR PERFORMANCE OF STEEL HIGH-RISE BUILDINGS
}

\author{
B. Danjuma ${ }^{1, *}$ and O. S. Abejide ${ }^{2}$ \\ 1, 2, Department of Civil Engineering, Ahmadu Bello University, Zaria. Kaduna State, NIGERIA \\ E-mail addresses: ${ }^{1}$ danjumabilkisu15@gmail.com, ${ }^{2}$ abejideos@yahoo.com
}

\begin{abstract}
The study carried out an assessment of the non-linear performance of high-rise buildings in Nigeria and countries of similar earth-tremor records. Symmetric, regular Steel Dual-Concentric (chevron) Braced Frames (SD-CBF) building model was idealized, and its elastic design and nonlinear-static analysis were executed using SAP2000 v15 to determine the response of the building to the highest magnitude of 'earth tremor ever experienced in Nigeria which was about 4.8 on the moment magnitude scale. From the assessment, it was inferred that, the buildings will perform well for the purpose it was designed, as the onset of inelastic weakening or instability of the building can easily be detected from the plastic response of the braces and so easily retrofitted with consequent savings in human lives and economy. It was established that the buildings will do well on all soil types specified by EC8 (2004) and increase in the Peak Ground Acceleration which is an indicator of the seismic hazard, increases the global displacement of the buildings.
\end{abstract}

Keywords: Earth-tremor, SD-CBF, Finite Element, Peak Ground Acceleration and Seismic Hazard.

\section{INTRODUCTION}

Earthquake is one of the most serious and devastating natural disasters experienced by man. It has indeed caused direct damages when the seismic disturbance weakens and collapses buildings and other infrastructures not built to withstand the tremors. This has caused great loss of lives and other damages such as landslides, mudslides, fires, tsunamis, soil liquefaction and so forth. In recent decades, the civil engineering practices world-wide has come a long way in the analysis and design of structures against seismic actions. Structures built prior to this scenario may need repair or retrofit, and their analyses require much effort, as assumptions about their strength, stiffness or ductility may not be dependable, since their design criteria were either rule of thumb or at best deterministic [1].

Steel is one of the most widely used materials for building construction in the world .The inherent strength; toughness and high ductility of steel are characteristics that are ideal for seismic analysis and design. Moment Resisting Frames (MRFs) have low elastic stiffness; therefore, can require large member sizes to keep lateral drifts within mandatory limits demanded by seismic codes. Load-deflection (P- $\Delta$ ) effect is another problem associated with such structures in high rise buildings and so could not fulfill serviceability requirements. Structural response is increased in Steel Moment Resisting Frames by introducing steel bracings in the structural system. Bracing can be applied as concentric bracing or eccentric bracing. There are ' $n$ ' number of possibilities to arrange steel bracings, such as cross bracing ' $\mathrm{X}$ ', diagonal bracing ' $\mathrm{D}$ ', ' $\mathrm{K}$ ' and ' $\mathrm{V}$ ' type bracing. These bracings are arranged to form vertical trusses and then lateral loading is resisted by truss action. Therefore, bracings allow the system to obtain a great increase in lateral stiffness with minimal added weight. Thus, they increase the natural frequency and usually decrease the lateral drift. Ductility is developed through inelastic action in braces. Failure occurs because of yielding of truss under tension or buckling of truss under compression [2].

\footnotetext{
* Corresponding author, tel: +234-813-380-6987
} 
Concentrically Braced Frames (CBFs) are a class of structures resisting lateral loads through a vertical concentric truss system, the axes of the members aligning concentrically at the joints. CBFs tend to be efficient in resisting lateral forces because they can provide high strength and stiffness, economy and ease of construction. These characteristics can also result in less favorable seismic response, such as low drift capacity and higher accelerations. CBFs are a common structural steel or composite system in areas of any seismicity [3]. Because of the obstructions caused by cross-braces, chevron braces are often preferred to allow for door and windows openings. Conventional chevron frames consist of two braces forming an inverted V-shape and meeting the upper storey beam at mid-span. While the fulfillment of serviceability limit state requirements is easy to obtain by means of such structural typology, some uncertainties arise about its adequacy to resist strong seismic actions by undergoing severe excursions in the non-linear range [4].

This behaviour is affected by a number of quite complex and not easily predictable aspects, such as the performance of end connections, the inplane and out-of-plane overall buckling of compressed members and all the local damage phenomena, that is, local buckling, and low cycle fatigue, fracture propagation, related to the inelastic cyclic behaviour under axial and bending forces. Because of the inherent drawbacks of both MRFs and CBFs, MRF-CBF dual systems are more and more attracting the interest of researchers and practitioners as they constitute a reliable structural scheme which combines the advantages of both structural typologies, because of the exploitation of the local ductility supply of the beams of the moment resisting part and of the lateral stiffness provided by the diagonal members of the braced part. Therefore, dual systems constitute an effective structural solution able to satisfy ultimate and serviceability limit state requirements [5].

A multi-story steel frame building with braces and shear walls, which was subjected to a simulated combined earthquake and dead loads was modeled by [6] using SAP2000. The building was assumed not too close to the seismic source (September 11th 2009 earth tremor in Abeokuta, Nigeria) [7], 22.5km from the site

Consequently, this current work employs Steel DualConcentric Braced Frames, SD-CBF for Non-Linear Static Analysis using the available data from [6], in order to evaluate the performances of the combination of moment resisting frames and concentric braced (chevron) frames in the study area (Abeokuta) and, generally in Nigeria, and other similar African countries. This is because the seismicity of other similar countries like Nigeria rarely exceeds that predicted for Abeokuta.

\subsection{Non Linear Static (Pushover) Analysis}

The pushover analysis of a structure is a static nonlinear analysis under gravity loads and gradually increasing lateral loads. The equivalent static lateral loads applied approximately represent tremor induced forces. The analysis is carried out up to failure; thus it enables determination of collapse load and ductility capacity. On a building frame, plastic rotation is monitored, and a lateral inelastic force versus displacement response for the complete structure is analytically computed that would indicate any premature failure or weakness.

The pushover procedure is either force-controlled or displacement-controlled. The displacement-controlled is preferred due to some numerical difficulties with the former as noted by [8], hence it is used here. In displacement-controlled procedure, specified displacements are sought assuming that the magnitude of applied load is not known in advance. The magnitude of load combination is amplified or reduced as necessary until the control displacement reaches a specified value or the building collapses, whichever comes first. Generally, roof displacement at the centre of mass of structure is chosen as the control point of displacement. The internal forces and deformations computed at the target displacement are used as estimates of inelastic strength and deformation demands that have to be compared with available capacities for a performance check.

Models with plastic hinges defined on the momentrotation relation as specified in SAP2000 were used to simulate the elasto-plastic behaviour of the building and hence, obtain the pushover curve.

\section{RESEARCH METHODS}

The finite element modeling, design and pushover analysis of the structure was performed in [9]. The structure is a fifty-storey office building, with threeby-three bay, and each bay-width is 7.5metres, comprising dual frames, SD-CBF. A Dual-Frame is a structural typology obtained by combining two structural sub-systems that work in parallel and contribute together to dissipate seismic energy induced by ground motion. In case of SD-CBF, a sub- 
system is a Concentrically Braced Frame (CBF), and the other is a Moment-Resisting Frame (MRF). The gravity loads resisting system consists of composite floor system modeled as rigid diaphragms, which consist of lightweight concrete of dry density $19.00 \mathrm{kN} / \mathrm{m}^{3}$ over trapezoidal profiled steel decking. The Eurocode $4[10]$, recommendation is that anticrack mesh (A142, A193, A252 or A393) which comprise $0.2 \%$ of slab area for un-propped spans and $0.4 \%$ of slab area for propped spans may be used. The considered building is designed to sustain dead and live loads. Dead loads were determined from the weight of the elements constituting the flooring system. Each floor consists of a $0.11 \mathrm{kN} / \mathrm{m}^{2}$ unit weight metal deck with $130 \mathrm{~mm}$ thick lightweight density concrete slab leading to a permanent load of $3.6 \mathrm{kN} / \mathrm{m}^{2}$, while the imposed load was $3.00 \mathrm{kN} / \mathrm{m}^{2}$ comprising $2.25 \mathrm{kN} / \mathrm{m}^{2}$ imposed load (category B) and $0.75 \mathrm{kN} / \mathrm{m}^{2}$, movable partition. The roof permanent load was assumed to be $0.90 \mathrm{kN} / \mathrm{m}^{2}$ and its live load $0.6 \mathrm{kN} / \mathrm{m}^{2}$; the roof can only be accessible for normal maintenance and repair. The plan, 2-dimensional and 3-dimensional sections of the building are shown in Figure1.

The entire building was modeled using a single steel material property. Modelled as bilinear elasto-plastic, the steel is classified as S355 European structural steel and has a Young's modulus of $210,000 \mathrm{~N} / \mathrm{mm}^{2}$ and yield strength of $355 \mathrm{~N} / \mathrm{mm}^{2}$ [11]. The building was assumed not too close to the seismic source; however, if a large magnitude event is produced at the source, then the building can be affected by the earthquake. Any high rate of seismic activity from the source also means that there is a very high tendency that the building, when completed (or during construction), will not take too long before experiencing a seismic activity. Thus, a proper modification of buildings in such area, to withstand seismic forces is substantially important. Necessary information about the building location and the soil condition at the site as obtainable at the study area are presented as follows: stiff soil with a shear wave velocity of $250 \mathrm{~m} / \mathrm{sec}$ [6], which translates to type C soil in [12], nearest seismic source is $22.5 \mathrm{~km}$ from the site. The model was designed in detail in accordance with Eurocode 3 [11] and Eurocode 8 [12], in SAP2000v15 using the Modal response spectrum (linear dynamic) analysis with five per cent (5\%) damping elastic response spectrum. The sections chosen in the preliminary design [13] were re-analysed and re-designed; stress checks were run, and the sections updated. The beam sizes consider the contributions of the slabs and are uniform throughout the frame. The column sizes, however, change every ten floors and decrease as height increases. The Strong Column-Weak Beam (SCWB) theory was considered in their design.
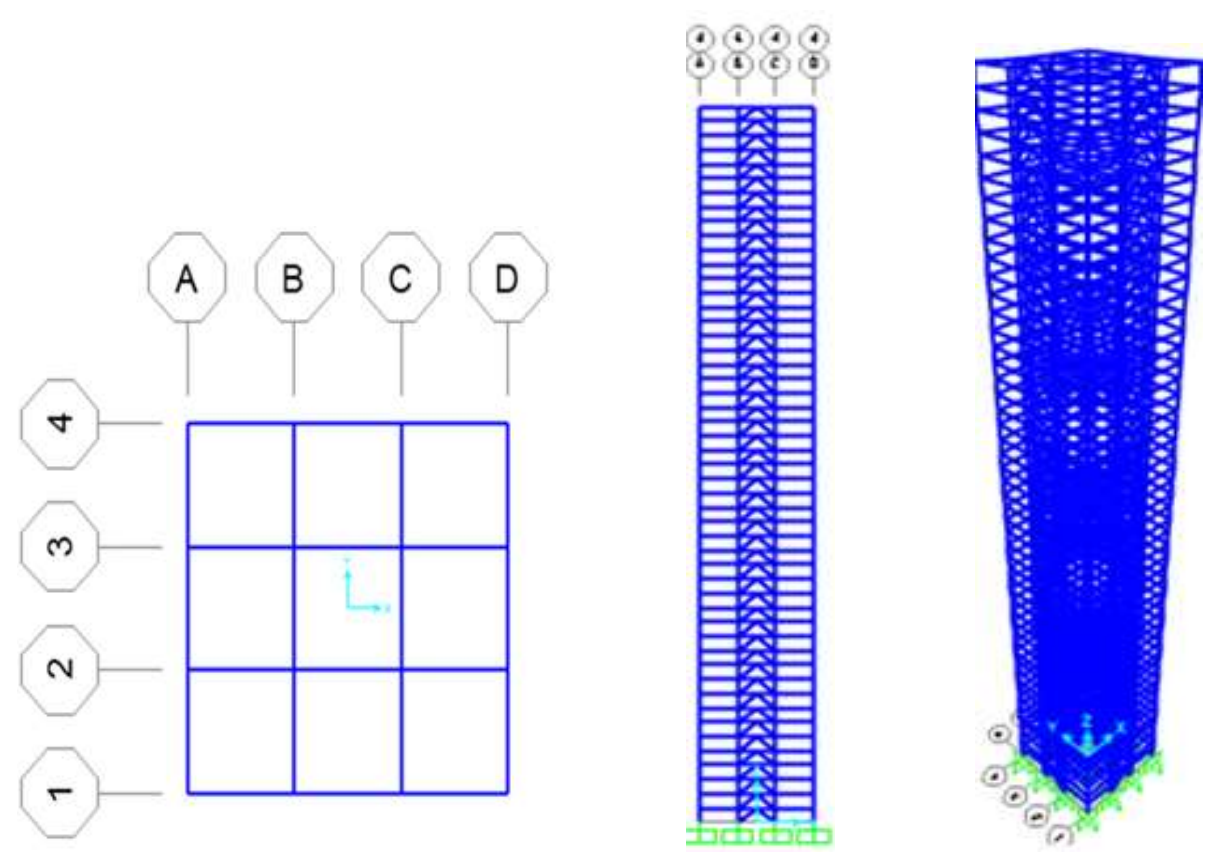

Figure 2: Plan, 2-dimensional and 3-dimensional elevation of the modelled building (SAP2000v15) 
For the nonlinear static analysis, the default hinges provided by SAP2000 v15 were applied which include the bending plastic hinge (M3) for the two ends of the beams that is at relative ends 0 and 1 , the biaxial bending hinge (P-M3-M2) for the columns at both ends and the axial hinge $(P)$ at the centre of the braces. The total number of applied hinges amount to 4400 on the building. These plastic hinges were used to simulate the elasto-plastic performance of components when they are yielding or post-yielding in SAP2000. The pushover analysis in SAP 2000 involves:

(i) Defining and assigning hinge properties to relevant elements

(ii) Defining static pushover load case.

(iii) Analysis which involves application of the gravity load and lateral load pattern and the determination of their effects on the building

(iv) Reviewing the pushover deformed shape and curve in order to determined performance of the building.

\section{RESULTS AND DISCUSSION}

The different sizes of the beams, columns and braces obtained after analysis and design iteration in SAP2000 v 15 from the preliminary member sizes are shown in Table 1 . A total of 12 modes of vibration, with different periods and frequencies were considered while the modal participation factors culminated into $100 \%$ static participation and $99.69 \%$ dynamic participation. This is more than satisfactory, as Eurocode 8 [12] requires at least $90 \%$ of the effective modal masses for the modes to be accounted for.

During the pushover analysis, three hinges appeared on chevron braces in the west-east direction close to mid-height of the building at the 16th push step. With the number of steps increased, more plastic hinges continuously appeared. Beams and columns of the whole model were still in the elastic stage.

These hinges have non-linear states defined as 'Immediate Occupancy' (IO), 'Life Safety' (LS) and 'Collapse Prevention' (CP) within its ductile range. This is usually done by dividing $\mathrm{B}-\mathrm{C}$ into four parts and denoting IO, LS and CP, which are states of each individual hinges. There are different criteria for dividing the segment BC. For instance, one such specification is at $10 \%, 60 \%$, and $90 \%$ of the segment BC for IO, LS and CP respectively. The IO performance level implies light structural damage, no permanent drift, substantially original strength and stiffness; the LS implies moderate damage, some permanent drift, residual strength and stiffness; while the $\mathrm{CP}$ indicates Severe damage, large permanent drifts, little residual strength, stiffness and building near collapse.

At the 19th step, 10 hinges moved into IO level while, 6 hinges moved from LS to CP level. Up till the 20th step, where 40 hinges failed completely with a base shear of about $43.12 \times 10^{3} \mathrm{kN}$ as shown in Figure 2; while the columns and beams did not yield at all. The sequences of hinges formation for a few selected steps with colours indicating structural performance are shown in Figure 3 and 4.

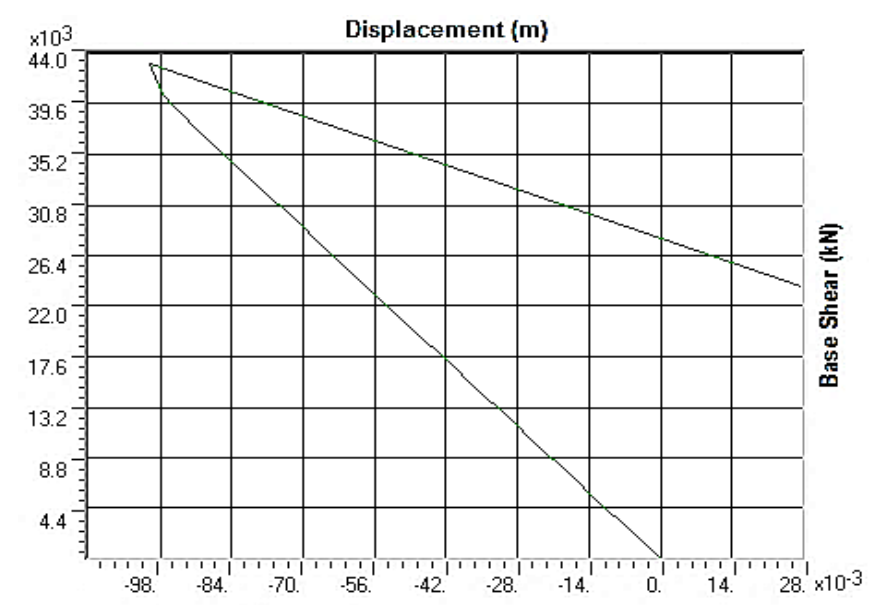

Figure 2: Relationship between Resultant Base Shear to Monitored Displacement (SAP2000)

The maximum global displacement observed from the graph in Figure 2 is approximately $0.1 \mathrm{~m}$; this may be due to the fact that the pushover analysis considered the contribution of other modes of vibration as opposed to the fundamental mode only. The advantage of this phenomenon is that the global displacement is significantly minimized.

These results confirm the effectiveness of dualsystem concept, The MRFs being the secondary subsystem able to withstand the earthquake forces after loss of lateral strength and stiffness has occurred in the primary sub-system (braces) did not yield. In general, the SD-CBFs showed poor distribution of deformation, with damage concentrations in a limited number of braced storeys of the buildings.

Recent works by $[3,14-16]$ and others, together with experimental evidences $[14,17,18]$ have pointed out criticisms and potentialities of steel concentric braced frames (CBF) in seismic areas. 
Table 1: Location and dimension of steel sections

\begin{tabular}{llccccc}
\hline \multirow{2}{*}{ SECTION NAME } & \multicolumn{1}{c}{ LOCATION } & \multicolumn{4}{c}{ SECTION DIMENSION } \\
\cline { 3 - 6 } & & $\mathrm{h}_{\mathrm{w}}(\mathrm{mm})$ & $\mathrm{b}_{\mathrm{f}}(\mathrm{mm})$ & $\mathrm{t}_{\mathrm{f}}(\mathrm{mm})$ & $\mathrm{t}_{\mathrm{w}}(\mathrm{mm})$ & $\mathrm{A}\left(\mathrm{mm}^{2}\right)$ \\
\hline Ten & Columns for levels 1-10 & 2000 & 1850 & 300 & 150 & 1320000 \\
Twenty & Columns for levels 11-20 & 1900 & 1650 & 280 & 120 & 1084000 \\
Thirty & Columns for levels 21-30 & 1700 & 1400 & 250 & 100 & 820000 \\
Forty & Columns for levels 31-40 & 1400 & 1200 & 200 & 80 & 560000 \\
Fifty & Columns for levels 41-50 & 1100 & 900 & 150 & 60 & 318000 \\
Beam & Beam for all levels & 340 & 310 & 39 & 21 & 30300 \\
Brace & Brace for all levels & 300 & 250 & 34 & 16 & 20712 \\
\hline
\end{tabular}
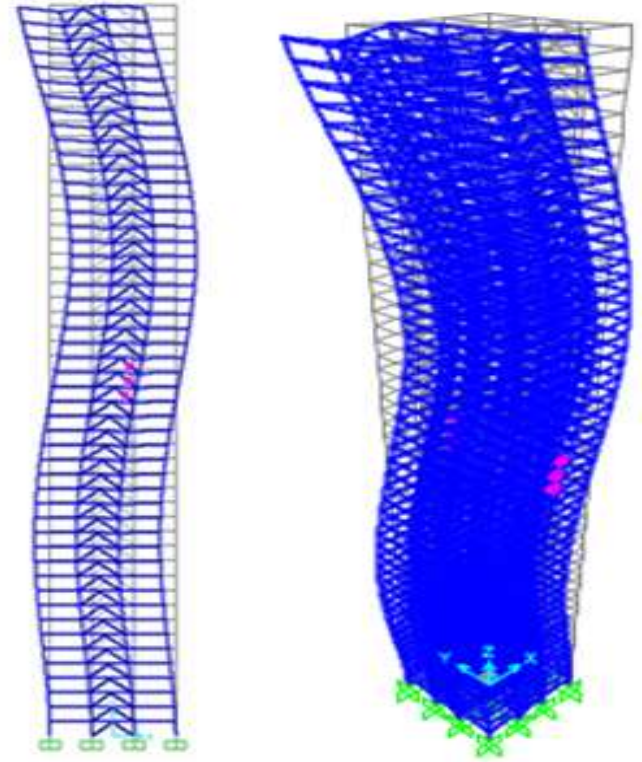

Figure 3: Deformed shape of the building in $2 D$ and 3D at the 16th Push step.

In particular, it has been observed that plastic mechanisms characterized by the yielding of diagonals, while preventing the yielding/buckling of beams and columns and the failure of connections, lead to good performances of CBFs in terms of ductility and energy dissipation. In an illustrated assessment and retrofit procedure for CBFs by [19], different strategies were considered, all based on the substitution of diagonals with new standard profiles able to improve the global seismic performance in terms of lateral stiffness, damping and energy dissipation.

As the performance of the structure is being investigated for Nigeria and other similar countries, it was necessary to determine the influence of ground types on either the base shear or displacement of the building, as adapted from [12] which described the soils stratigraphic profiles and parameters. Ground type A consist of rock or rocklike material, type B
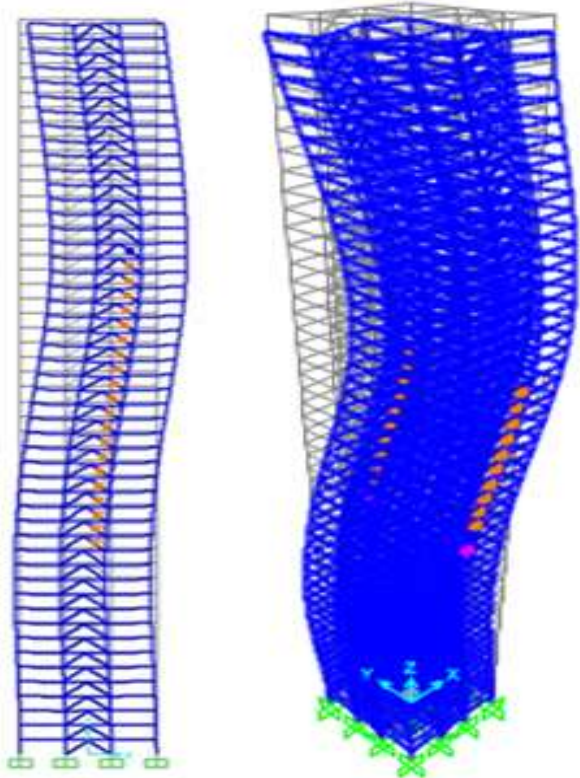

Figure 4: Deformed shape of the building at Push step 20, with plastic hinges.

consist of very dense sand, gravel or stiff clay, type C consist of dense sand, gravel or stiff clay, type D is composed of loose-medium cohesion less soil and type $\mathrm{E}$ consist of surface alluvium underlain with stiffer material at some depth. This was used to account for the influence of local ground conditions on the soil types. Figure 5 indicates an increase in displacement in the building with change in soil types A-E

In [11] the seismic hazard is described by the value of the Peak Ground Acceleration, PGA, $\left(a_{g}\right)$. The attenuation of $\mathrm{a}_{\mathrm{g}}$ is given by [20]:

$$
\log \left(a_{g}\right)=-1.48+0.27 M-0.92 \log R
$$

Where,

$M$ is the Magnitude and $R$ is the epicenter distance.

The expression is valid for $4<M<7.3$, and for $3 \mathrm{~km}$ $<R<200 \mathrm{~km}$. Of course, an increase in the magnitude of earthquake reduces with increase in distance. 


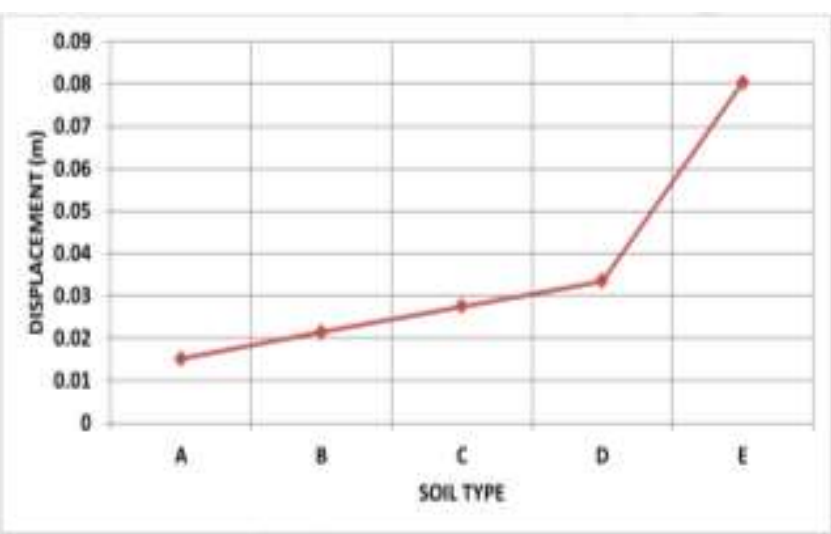

Figure 5: Relationship between Displacement to Soil Type

Equation (1) yielded a value of approximately $0.1 \mathrm{~g}$ $\left(0.98 \mathrm{~m} / \mathrm{s}^{2}\right)$ that was used in designing the building. The effect of increasing peak ground acceleration was also determined for the building as shown in Figure 6.The relationship between the Peak Ground Acceleration and Displacement indicated that the displacement of the building increases as the seismic hazard increases in terms of the PGA.

\section{CONCLUSION}

The modelling, design, and non-linear static (pushover) analysis of a fifty storeyed symmetric SDCBF building was undertaken in this study with the aid of finite element coded in SAP2000 v15 software. From the study, the following findings were made:

Steel sections for the beams, columns and braces as determined from the design are shown in Table 1.

A base shear of $43.12 \times 10^{3} \mathrm{kN}$ was obtained for the building corresponding to a global (lateral roof) displacement of approximately $0.1 \mathrm{~m}$.

A maximum global displacement of approximately $0.1 \mathrm{~m}$ was obtained from the pushover analysis which is much lower than the code limit (FEMA 350, 2000) of $2 \%$ of the height of the building. This may be attributed to the contribution of other modes of vibrations to the pushover analysis and possibly the use of bracing which increases the building stiffness.

It was established that the building will do well on all soil types specified by EC8 [11]; though special attention should be given to soil type $E$.

It was also found that increase in the PGA which is an indicator of the seismic hazard increases the global displacement of the building.

Based on the result of the study carried out, the following recommendations are made:

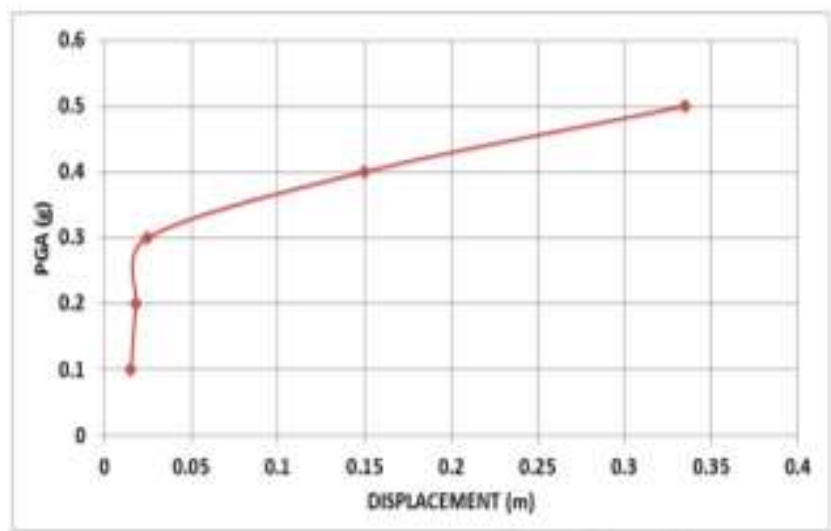

Figure 6: Relationship between Peak Ground Acceleration to Displacement

a) The overall behaviour of the building indicates that, it will perform well for the purpose it was designed, in Nigeria and other similar countries, as the onset of inelastic weakening or instability of the building can easily be detected from the plastic response of the braces which again can be easily retrofitted with consequent savings in human lives, economy and property.

b) A safety factor of 1.25 to 1.5 maybe applied in order to increase structural safety and robustness in the event of unexpected greater seismicity.

Furthermore, some research areas that may be explored in future include:

a) Assessment of the performance of gusset plates and connections of such or similar high-rise buildings.

b) A non-linear dynamic (Time History Analysis) of the building may be carried out to reconfirm the results obtained.

c) Incorporating various types of irregularities (vertical and horizontal) in the analysis, design and assessment of high rise buildings.

\section{REFERENCES}

[1] K. N. Manjula, P. Nagarajan, and M. T. P. Madhavan, "A comparison of basic pushover methods," International Refereed Journal of Engineering and Science, vol. 2, no. 5, pp.1419. 2013

[2] M. Mubeen, K. N. Khan, and M. I. Khan, "Seismic analysis of steel frames with eccentric bracings using Pushover Analysis," International Journal of Advanced Technology in Engineering and Science, vol. 3, no. 6, pp. 226-237, 2015.

[3] R. Sabelli, W. C. Roeder, and F. J. Hajjar, "Seismic design of steel special concentrically 
braced frame systems: A guide for practicing engineers," NEHRP Seismic Design Technical Brief No. 8, , Gaithersburg, MD, NIST GCR 13917-24. 2013.

[4] M. Bruneau, C. M. Uang, and A. Whittaker, Ductile Design of Steel Structures, McGraw-Hill, Network. 1998.

[5] A. Longo, R. Montuori, and V. Piluso, V. "Seismic design of chevron braces coupled with MRF fail-safe systems."Earthquakes and Structures, 2015.

[6] P. O. Awoyera, F. J. Ogundeji, and A. P. Aderonmu, "Simulated combined earthquake and dead load lateral resistance building systems using Nigeria seismic data." J. Mater. Environ. Sci., vol.7, no.3, pp. 781-789, 2016

[7] O. U. Akpan, I. A. Monday, A. Y. Tahir, A. A. Abraham, S. O. Chiedu, S. O. Adetola, and I. O Michael, "An evaluation of the 11th september, 2009 earthquake and its implication for understanding the seismotectonics of south Western Nigeria" Open Journal of Geology, vol. 4, no.10, pp. 542-550, 2014.

[8] S. Oguz. "Evaluation of pushover analysis Procedures for frame structures" M.S Thesis, TheGraduate School of Natural and Applied Sciences of Middle east Technical University, 2005. [Accessed November 16, 2017].

[9] SAP2000 v15.0.0. (2010) "Integrated finite element analysis and design of structures" Available: Computers and Structures, Inc., Berkeley, California, USA.

[10] EN 1994-1-1 Eurocode 4: Design of composite steel and concrete structures - Part 1: General rules and rules for buildings. $1^{\text {st }}$ ed. Brussels: BSi, 2005.

[11] EN 1993-1-1 Eurocode 3: Design of Steel Structures Part 1-1: General rules and rules for buildings. $1^{\text {st }}$ ed. Brussels: BSi, 2005

[12] EN 1998-1-1Eurocode 8: Design of Structures for Earthquake resistance - Part 1: General rules, seismic actions and rules for building. $1^{\text {st }}$ ed. Brussels: BSi, 2004.
[13] B. Danjuma, O. S. Abejide, and J. M. Kaura, " Preliminary design of high rise buildings for global adaptation using the linear static method" Nigeria Journal of Technology, vol. 37, no.3, pp. $570-575,2018$.

[14] A. Kanyilmaz, A. C. Castiglioni, and H. Degèe, " Full Scale Experimental Assessment of Concentrically Braced Steel Frames Designed for Moderate Seismicity" Proceedings, 16th World Conference on Earthquake, Santiago Chile. Paper ID 3271, 2017

[15] A. R. Jazany, I. Hajirasouliha,S. A. Moghadam, H. Kayhani, and H. Farshchi, "Analytical Study on the Seismic Performance of Steel Braced Frames with Masonry Infill" 2016. Available: eprints.whiterose.ac.uk [Accessed January 7, 2018].

[16] M. H. Mayez Akkari, "Seismic Behaviour Prediction of Concentrically Braced Steel Frames" Thesis Paper 189, 2015. Available: http://scholarworks.uaeu.ac.ae/all theses [Accessed December 16, 2017].

[17] P. Uriz, and S. A. Mahin, "Seismic performance assessment of concentrically braced steel frames," 13th World Conference on Earthquake Engineering Vancouver, B.C., Canada, Paper No. 1639, August 1-6, 2004.

[18] A. D. Sen, C. W. Roeder, J.W. Berman, D.E. Lehman, C.H. Li, A.C. Wu; and K.C. Tsai, "Experimental Investigation of Chevron Concentrically Braced Frames with Yielding Beams," J. Struct. Eng., vol. 142, no.12. 2016.

[19] A. Rasulo, and E. Grande, "Use of OpenSees for the validation of a simplified procedure for the seismic assessment and retrofit of steel concentric braced frames" OpenSees Days Europe 2017, 1st European Conference on OpenSees Porto, Portugal, 19-20 June 2017.

[20] P. Bisch, E. Carvalho, H. Degee, P. Fajfar, M. Fardis, P. Franchin, M. Kreslin, A. Pecker, P. Pinto, A. Plumier, H. Somja, G. Tsionis "Eurocode 8 Seismic Design of Buildings Worked Examples" Presented at the Workshop "EC 8: Seismic Design of Buildings", Lisbon.2011 